Brazilian Journal

of Chemical

ISSN 0104-6632

Engineering

\title{
BIODEGRADATION OF ACRYLIC PAINTS: PROCESS MODELLING OF BIOCIDE EFFECT ON BIOMASS GROWTH AT DIFFERENT TEMPERATURES
}

\author{
V. Piemonte ${ }^{1}$, F. Francioni $^{1}$, M. Capocelli ${ }^{1}$ and M. Prisciandaro ${ }^{2 *}$ \\ ${ }^{1}$ Faculty of Engineering, University Campus Bio-Medico of Rome, \\ via Alvaro del Portillo 21, 00128 Rome, Italy. \\ ${ }^{2}$ Department of Industrial and Information Engineering and of Economics, University of L'Aquila, \\ viale Giovanni Gronchi 18, 67100 L'Aquila, Italy. \\ E-mail: marina.prisciandaro@univaq.it
}

(Submitted: November 27, 2015; Revised: February 28, 2016; Accepted: March 31, 2016)

\begin{abstract}
Acrylic paint, notwithstanding the attention paid during the production process, couldbe contaminated by bacteria. This is a consequence of microbiological residuals on the can, resulting in the alterationof paint characteristics. It is therefore necessary to provide an in-canpreservation of the paint by using a biocide.In this paper, the evolution of an in-can system, using a thermo-fluid dynamic model is presented; as a biocide, 2-methyl-4-isothiazolin-3-one, commercially known as MIT,was considered. The model was implemented on gPROMSsoftware and it was possible to determine the inhibitory concentration of the biocideinorder to guarantee both the protection of the can and the protection of thecover phase. To develop the model, kinetic parameters have been found by fitting available literature experimental data. As far as the thermodynamical parameters, theequilibrium between liquid and vapor phases was described bythe NRTLmodel (ASPEN Plus). The model has been validated through a comparison with experimental literature results using MIT alone and a mixture of biocides (MIT/BIT). The main results are that, at the maximum allowable concentration (100 ppm as imposed by law), the MIT biocide is able to protectthe paint for long periods, even when the temperature varies cyclically from 10 to $40^{\circ} \mathrm{C}$.
\end{abstract}

Keywords: acrylic paints; biocide; MIT; microbiological contamination; modelling.

\section{INTRODUCTION}

To meet the growing demand for environmentally friendly products, the organic solvents used in the formulation of paints areincreasingly replaced by waterbased systems. This leads, however, to amore pronounced problem of microbiological contamination. Typically, paints contain alarge number of components (thickening, binders and minor ingredients, such as coalescing agents or defoamers, anticorrosion agents)(Ulb rich and Kalendová, 2013; Del Amo et al., 2002) some of which are easily attacked bymicroorganisms.A wide range of bacteria, molds and yeasts can infect and cause the deterioration of water-based paints and they may originate from a number of sources(Ravikumar et al., 2012; Bethencourt et al., 2003; Obidi et al., 2009). The principal contaminants of paints are bacteria and rarely fungi, which use the organic compounds of the paint to grow and multiply (Olufemi et al., 2013). For sanitary reasons the bacterial proliferation must be prevented by adding efficient preservatives in the paint itself. The use of effective broad-spectrum biocides, together with good manufacturing processes and plant hygiene, may enable long-term microbiologically troublefree production to take place (Karsa and Ashworth, 2002). The right choice of a preservative systemdepends on the kindof microorganism, the physicochemical

*To whom correspondence should be addressed 
compatibility, the toxicity of the biocidal product and its finalcharacteristics. Microbial infections may occur during the manufacturing stages of paint production and during the storage as packaged product (La Rosaet al., 2008).As a matter of fact, when subject to different temperatures, the in-canproduct could evaporate and then condense again under the cover of the can. Since biocides are not volatile substances, they are present in very small quantities in the cover phase; the bacteria are thus free to proliferate. Therefore, paints require different biocides for their effective protection: a biocide to protect the paint inside the can itself (in-can protection), and onefor the protection of the layer of paint when applied to surfaces (Contant et al., 2010).The presence of microorganisms in the layer of paint applied on the surface is not desirable since they cause discoloration of the paint, damaging it considerably. Microbial growth is common in outdoor environments under certain conditions of temperature and humidity. In indoor environments with high humidity the growth of fungimay occur (Kham and Karuppayil, 2012). The microorganisms cover the paint surface with a thin layer of cells. Moreover, the presence of microorganisms due to the increase of the porosity of the layer of paint, causes a decrease in its physical resistance and allows moisture to penetrate the treated surface, which in the case for example of a wood surface can cause serious corruption problems (Unger et al., 2013; Goossens et al., 2003).

For all the above mentioned reasons, the presence of biocide in paint is therefore mandatory.

The inhibition of the growth of microorganisms by means of biocidal products has been explained as the result of different actions implemented by the biocide, such as the destruction of the cell membrane, the inhibition of metabolic reactions, the variation of intracellular $\mathrm{pH}$ and the accumulation of toxic anions. There are numerous methods described in the literature for the determinationof a biocidal product efficacy, both for storage in-can as well as if paint is applied on surfaces. The most used methods are the ASTM Standards (2012), particularly ASTM D2574-86(Test Methods for Resistance of Emulsion Paints in the container to attack by microorganisms), ASTM D 3273-86 (Test Method for Resistance to Growth of Mold on the surface of interior coatings in an environmental chamber), ASTM D 3456-86 (Practice for determining by exterior exposure tests the susceptibility of paint films to microbiological attack).

Heavy metals have been used for many years as biocidal compounds,but their use has been widely restricted in recent years, mostly because of new environmental decrees.The EuropeanUnion establishes some regulations about the biocides to be commercialized in Europe; from 01/05/2015 all the substances must be adequatedto the new statement and the biocide concentration in products has been considerably reduced.

Among available molecules, typically used biocides for in-can protection are:1,2-benzisothiazolin-3-one (BIT), 5-chloro-2-methyl-isothiazolin-3-one/2-methylisothiazolin-3-one (CMIT,MIT); formaldehyde donors. Biocides used for film protection are: zinc pyrithione, Carbendazim, octylisothiazolin-3-one (OIT). All these compounds are classified as sensitizing substances and there are restrictive concentration limitsto regulate their presence in paints and coatings, according to EUH208 valid from June 2015 (Chema, 2015).

In this paper, a MIT-basedbiocide (2-methyl-4isothiazolin-3-one) has been chosen to simulate the biocide hindering of microorganism proliferation inside a paint can, based on a previous more basic model (Piemonte et al., 2016). In details, we model the evolution of an incan system, evaluating the behavior of the bacteria in the presence of the biocide with the aim of determining the effect of biocide on biomass growth as a function of time and as well as the effect of temperature on bacteria proliferation inside the can. Unlike other available simulations, the present model allows one to consider the bacterial growth on the cover of the paint-can, underestimated in all the available experimental tests, focusing primarily on bacterial behavior in the bulk of the paint. The equilibrium between liquid and vapor phases is modeled by using the NRTL model; a kinetic model is developed to describe the biomass growth and substrate consumption. The model results are compared to available experimental data and it is used to predict the biomass and substrate evolution in the paint at different temperatures.

\section{MATHEMATICAL MODELLING}

The system shown in Figure 1 has been considered for simulation. It consists of three phases: a liquid phase $a$, representing the bulk of the paint contained in the can, a vapor phase $b$ and a liquid phase $c$ derived from evaporation and subsequent condensation of the paint under the lid.

The paint composition considered is the following: vinyl acetate (substrate 1 - S1): 6\% weight; monopropylene glycol (substrate 2 - S2): 2 weight $\%$; calcium carbonate: $6 \%$ weight; water (W): $85.99 \%$ weight;MIT (I): $0.01 \%$ weight $=100 \mathrm{ppm}$. The contribution of pigments (calcium carbonate) to the calculation of the phase equilibrium was neglected. Considering the specific weight of paint equal to $1.66 \mathrm{~g} / \mathrm{cm}^{3}, \mathrm{~S}^{0}=99597.4 \mathrm{~g} / \mathrm{m}^{3}, \mathrm{~S}^{0}=33200 \mathrm{~g} / \mathrm{m}^{3}, \mathrm{~W}^{0}=$ $1427000 \mathrm{~g} / \mathrm{m}^{3}, \mathrm{I}^{0}=165.9 \mathrm{~g} / \mathrm{m}^{3}$.

The biomass consideredconsists of five bacterial species in competition; in details, the strains consideredare:Pseudomonas aeruginosa, Pseudomonas fluorescens, Enterobacter aeruginosa, Alcaligenes faecalis, Staphylococcus aureus.

It is then necessary to describe the bacterial growth in the two liquid phases $a$ and $c$, also takinginto accountthe liquid-vapor balance of paint, which determines a different biocide concentration in the two phases $a$ and $c$. 


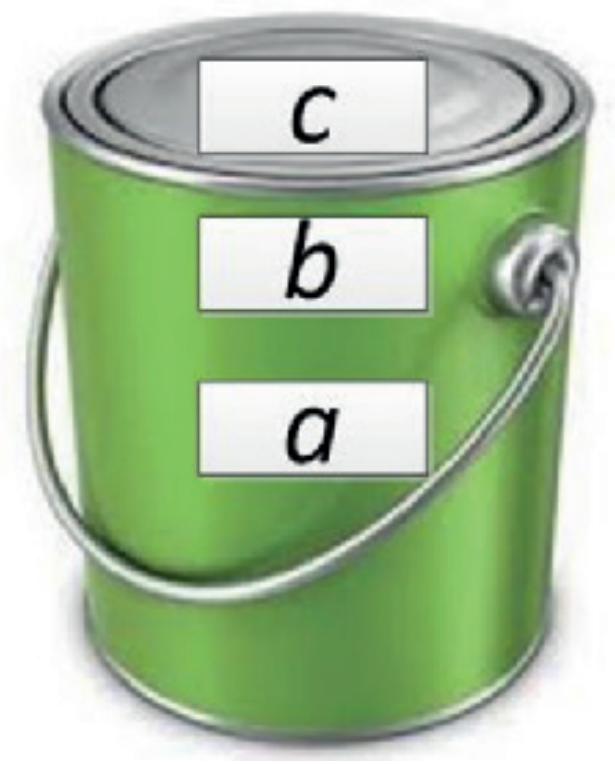

Figure 1. Sketch of the simulated system: a) liquid paint phase; b) air and vapor phase; c) condensed phase.

Consequently, the biocidewill have a different bactericidal action, with varying temperature of the system and initial concentration of biocide present in the phase $a$.

The equilibrium between the three different phases has been described by the thermodynamic model NRTL (Renon and Prausnitz, 1968). Model parameters have been derived from the database of Aspen Plus except for those related to MIT, whose properties have been defined by means of the predictive group contribution model UNIFAC (Pöllmann and Löbbecke, 1996). As a matter of fact UNIFAC is an activity coefficient model, like NRTL or UNIQUAC, but is basedon group contributions rather than molecular contributions and, with a limitednumber of group parameters and group-group interaction parameters, it can predict activity coefficients (AspenTech, 2011).

All the functional groups of the component were given and,through the UNIFAC method, all MIT propertieshave been estimated, including the binary interaction coefficients of the various subsystems. Finally, in phase $b$ the presence of airhas been assumed, which represents an incondensable for the phases $a$ and $c$; no chemical reactions are considered in the vapor-phase $b$ and the temperature difference between phases $c$ and $a$ is $\Delta \mathrm{T}=5^{\circ} \mathrm{C}$.

To describe the system from a dynamic point of view a Monod diauxic growth model has been used. The model based equations for biomass growth are reported below(Bailey and Ollis, 1986; Villadsen et al., 2011):

$$
\frac{d X}{d t}=\left(u_{1} v_{1}+u_{2} v_{2}\right) X
$$

where $X$ is the biomass concentration, $u_{i}$ and $v_{i}$ are cybernetic variables used to model the intracellular autoregulation devoted to the enzyme synthesis and cellular activity control, respectively. They can be calculated as:

$$
\begin{gathered}
u_{1}=\frac{\mu_{1}}{\mu_{1}+\mu_{2}} \\
u_{2}=\frac{\mu_{2}}{\mu_{1}+\mu_{2}} \\
v_{1}=\frac{\mu_{1}}{\max \left(\mu_{1}, \mu_{2}\right)}
\end{gathered}
$$

where the specific growths on substrates $S_{1}$ and $S_{2}$ are modeled by:

$$
\begin{gathered}
\mu_{1}=\frac{\mu_{\max 1} S_{1} e_{1}}{e_{\max 1}\left(k_{s 1}+S_{1}+\frac{S_{1}^{2}}{k_{i 1}}\right)} \\
\mu_{2}=\frac{\mu_{\max 2} S_{2} e_{2}}{e_{\max 2}\left(k_{s 2}+S_{2}\right)}
\end{gathered}
$$

being:

$$
\begin{aligned}
& e_{\max 1}=\frac{\alpha 1}{\mu_{\max 1+\beta 1}} \\
& e_{\max 2}=\frac{\alpha 2}{\mu_{\max 2+\beta 2}}
\end{aligned}
$$

where $\alpha$ and $\beta$ are the synthesis and degradation key enzyme constants (Kompala, 2013) and $k_{i 1}$ the substrate inhibition constant.

From Eqs. 6 and 7 it is evident that a substrate inhibitory effect has been considered for the degradation kinetics of substrate $S_{1}$. This effect has not been considered for substrate $S_{2}$. 
In order to take into account the biocide effect on biomass growth, Eq. 1 can be modified as follow:

$$
\frac{d X}{d t}=\left(u_{1} v_{1}+u_{2} v_{2}\right) X-K_{e i} X I
$$

where $I$ is the biocide concentration and $K_{e i}$ is the biomass lethality constant.

Then, the mass balance equations for enzymes, substrates and biocide can be written as:

$$
\begin{aligned}
& \frac{d e_{1}}{d t}=\frac{\alpha_{1} S_{1} u_{1}}{k_{s 1}+S_{1}}-\beta e_{1}-\frac{d X}{d t} \frac{e_{1}}{X} \\
& \frac{d e_{2}}{d t}=\frac{\alpha_{2} S_{2} u_{2}}{k_{s 2}+S_{2}}-\beta e_{2}-\frac{d X}{d t} \frac{e_{2}}{X}
\end{aligned}
$$

$$
\begin{gathered}
\frac{d S_{1}}{d t}=-\frac{\mu_{1} v_{1}}{Y_{x s 1}} X \\
\frac{d S_{2}}{d t}=-\frac{\mu_{2} v_{2}}{Y_{x s 2}} X \\
\frac{d I}{d t}=o
\end{gathered}
$$

where $Y_{x s 1}$ and $Y_{x s 2}$ are the yield growth factors.

First of all, the values of the kinetic parameters were evaluated through a fit of literature experimental data ofeach substrate.In details, for substrate $S_{1}$ it has been considered that:

$$
\begin{gathered}
\frac{d X}{d t}=\left(\frac{\mu_{\max 1} S_{1}}{k_{s 1}+S_{1}+\frac{S_{1}^{2}}{k_{i 1}}}\right) X \\
\frac{d S_{1}}{d t}=-\left(\frac{\mu_{\max 1} S_{1}}{k_{s 1}+S_{1}+\frac{S_{1}^{2}}{k_{i 1}}}\right) \frac{X}{Y_{x s 1}}
\end{gathered}
$$

while for substrate $S_{2}$ :

$$
\frac{d X}{d t}=\left(\frac{\mu_{\max 2} S_{2}}{k_{s 2}+S_{2}}\right) X
$$

$$
\frac{d S_{2}}{d t}=-\left(\frac{\mu_{\max 2} S_{2}}{k_{s 2}+S_{2}}\right) \frac{X}{Y_{x s 2}}
$$

Figures $2 \mathrm{a}-\mathrm{b}$ and $3 \mathrm{a}-\mathrm{b}$ show the best fit between the model and experiments for substrate $S_{l}$ (data fromKasperczyk et al., 2007) and $S_{2}$ (data fromToscano et al., 2009), respectively, while Table 1 reports the values of the resultant estimated kinetic parameters.

In details, for substrate S1 (vinyl acetate), the experiments used to fit the kinetic parameters are those by Kasperczyk and coworkers (2007), in which the Pseudomonas fluorescens strain utilizes vinyl acetate.

The experiments were performed in a batch reactor - volume about $2 \mathrm{~L}$ at constant optimal conditions for Pseudomonas fluorescens (temperature $30^{\circ} \mathrm{C}, \mathrm{pH}=7$ and aeration of 4 to $7 \mathrm{mg} \mathrm{dm}^{-3}$ of dissolved oxygen in the solution). The kinetics of vinyl acetate biodegradation were considered for the various initial concentrations of the substrate, from $\mathrm{S}_{0}=32 \mathrm{~g} \mathrm{dm}^{-3}$ to $400 \mathrm{~g} \mathrm{dm}^{-3}$.
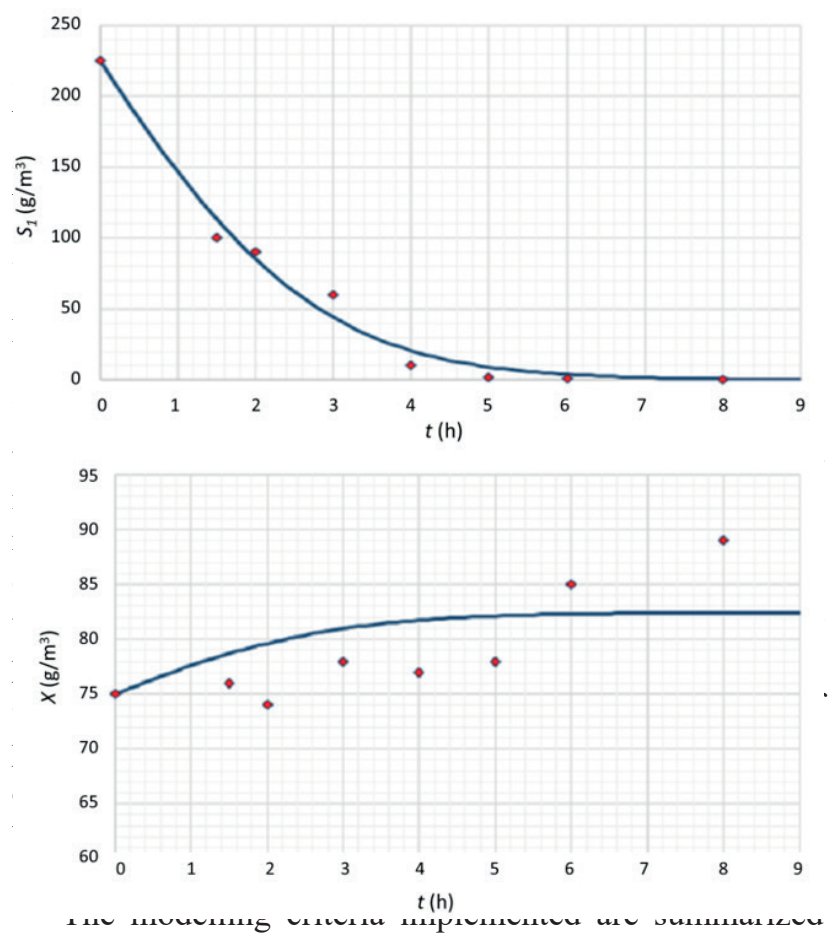

Figure 2. Kinetic parameter estimation for substrate S1 - Eqs (16-17). Line: model equations; symbols: experimental results (Kasperczyk et al., 2007). 

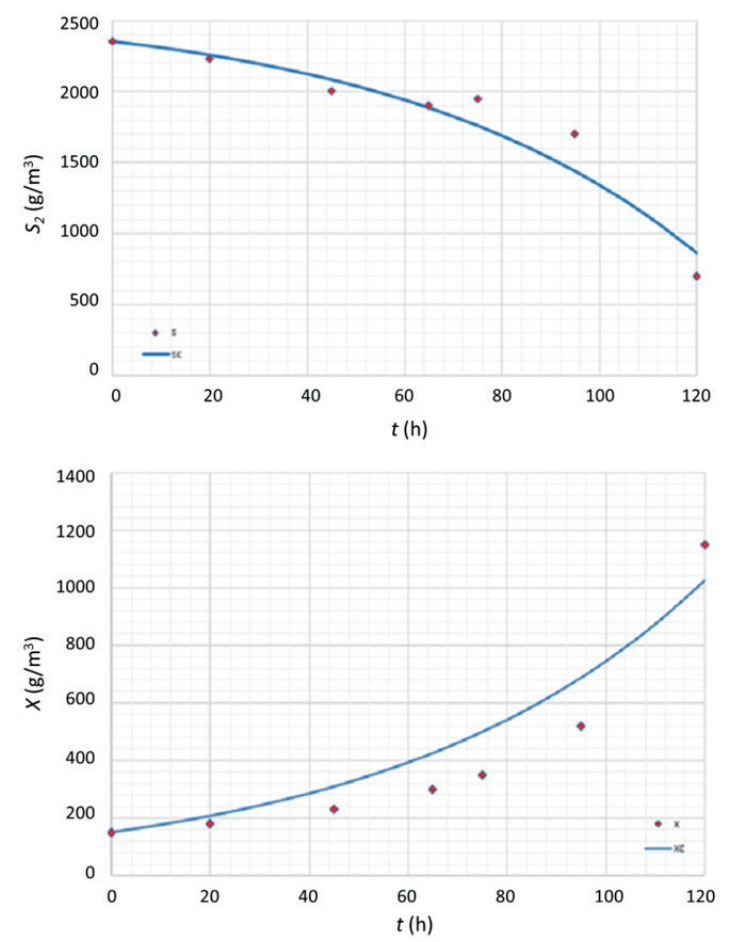

Figures 3. Kinetic parameter estimation for substrate S2 Eqs (18-19). Line: model equations; symbols: experimental results by Toscano et al. (2009).

Table 1. Kinetic parameters obtained from fitting.

\begin{tabular}{ccc}
\hline Parameter & Units & Value \\
\hline$\mu_{\max 1}$ & $\mathrm{~h}^{-1}$ & 0,072 \\
$k_{s 1}$ & $\mathrm{~g} / \mathrm{m}^{3}$ & 203,21 \\
$k_{i 1}$ & $\mathrm{~g} / \mathrm{m}^{3}$ & 18000 \\
$Y_{x s 1}$ & dimensionless & 0,033 \\
$\mu_{\max 2}$ & $\mathrm{~h}^{-1}$ & 0,0158 \\
$k_{s 1}$ & $\mathrm{~g} / \mathrm{m}^{3}$ & 0,01 \\
$Y_{x s 1}$ & dimensionless & 0,99 \\
\hline
\end{tabular}

in Figure 4. The thermodynamic model allows one to account for the phase partitioning. The kinetic modelling needs the evaluation (or experimental estimation) of some parameters.

Once the kinetic parameters have been estimated, the model is implemented to simulate the system of Figure 1 , reproducing the experimental points (symbols) derived from literature (Urška, 2011) that used a mixture MIT/ BIT.To fit experimental data relative to the mixture MIT/ BIT, the model, which considers only one biocide (MIT), was forced by increasing the value of the biomass lethality constant (see eq.10) by several orders of magnitude.

\section{RESULTS}

The model described above was validated through a comparison with available experimental results and then used to predict the behavior of biomass and substrate as a function of time. Figures 5 and 6 show the behavior of biomass $X$ in phase $a$ as a function of time with MIT as biocide (upper orange curve) and a mixture MIT/BIT (bluelower curve). The experimental points (symbols) derived from the literature(Urška, 2001) refer to a mixture MIT/BIT. The experimental conditions are: biocide initial concentration $I^{0}=1.78 \mathrm{~g} / \mathrm{m}^{3}$ and inoculum concentration $X_{a}^{0}=1.46 \mathrm{~g} / \mathrm{m}^{3}$ for Figure $5 ; I^{0}=199 \mathrm{~g} / \mathrm{m}^{3}$ and inoculum concentration $X_{a}^{0}=1.62 \mathrm{~g} / \mathrm{m}^{3}$ for Figure 6 .

As can be seen, the model fits very well the experimental condition for the mixtures MIT/BIT, while if the model considers the only MIT, it fails to describe the real system behavior.

Once tested the model reliability, a sensitivity analysis was carried out, structured into three groups of simulation runs.

A first group of simulations was intended to study the effect of biocide (only MIT) on the concentration profiles of biomass $(X)$ and substrates $(S 1, S 2)$ in the two phases $a$ and $c$, at the fixed temperature equal to $35^{\circ} \mathrm{C}$, and an initial concentration of biocide in phase $a, I_{a}^{0}=165.9 \mathrm{~g} / \mathrm{m}^{3}$, corresponding to $100 \mathrm{ppm}$ which is the maximum allowed by the legal limits (Chema, 2015).Figure 7 shows the biomass profile in phase $a\left(X_{a}\right)$ as a function of time: as can be seen, the biomass concentration decreases with time due to the presence of biocide, which at the tested concentration is sufficient to kill all microorganisms in about 15 hours. Figure $8 \mathrm{a}-\mathrm{b}$ shows the substrate consumption $\left(S 1_{a}-\right.$ see Fig. $8 \mathrm{a} ; S 2_{a}-$ see Fig. 8 b) always in phase $a$.

Figure 9 shows the bacterial concentration in phasec $\left(X_{c}\right)$, which has an initial lag phase, due to the acclimatization of bacteria; as a result, there is a phase of growth in which the substrate S1 is consumed (see Fig. 10a) and, once exhausted (after 250 hours, about ten days), the biomass starts to grow degrading S2 (Fig. 10b). The trend of the biomass in phasec shows the typical trend of a diauxic growth, previously described: when both substrates are consumed, the biomass slowly begins to decrease due to the biocidebut this occurs for very long times (about 1600 h), not shown here.

A second group of simulations was intended to study the effect of temperature on the distribution of biocide (only MIT) and biomass in the two phases, with the temperature ranging in the interval $20-40^{\circ} \mathrm{C}$, while keeping constant the biocide concentration $\left(I_{a}^{0}=165.9 \mathrm{~g} /\right.$ $\mathrm{m}^{3}$ ). With varying temperature in the interval $20-40^{\circ} \mathrm{C}$, the behavior of $X_{a}$ with time (not shown here) does not change significantly, even if the two substrate concentrations in phase $a$ decrease with increasing temperature, due to a higher evaporation (see Fig 11a-b). However, the biocide concentration is high enough at all the tested temperatures to exert its antimicrobial action (see Fig. 12).

On the contrary, the concentration of biomass in phase $c$ increases with temperature: at higher temperatures, the substrate amount that passes in phase $c$ grows, and so 


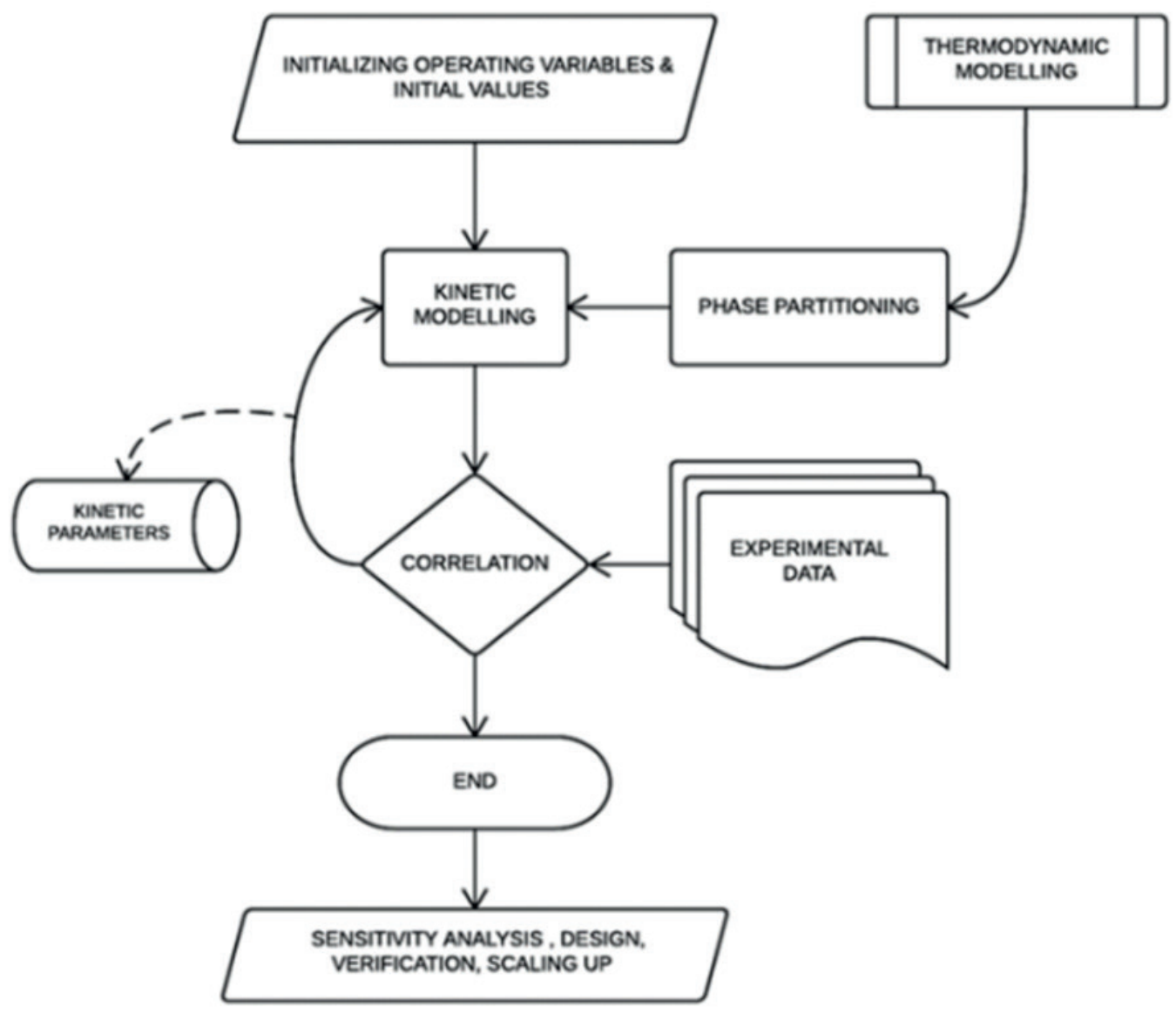

Figure 4. Logical scheme of the procedure implemented for simulating the system.

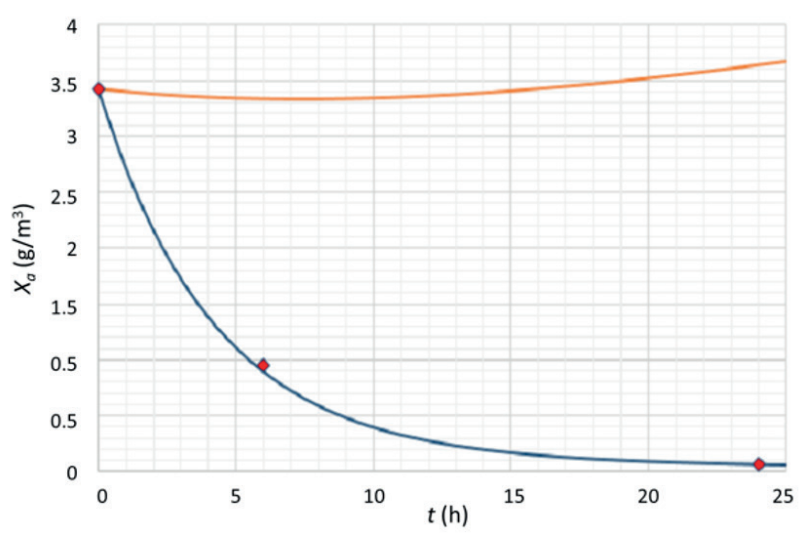

Figure 5. Biomass $X_{a}$ as a function of time; comparison between model and experimental results for MIT biocide (orange line) and MIT/BIT biocide (blue line); symbols: experimental results (Urška, 2011); $\mathrm{I}^{0}=1.78 \mathrm{~g} / \mathrm{m}^{3}$ and $\mathrm{X}_{\mathrm{a}}^{0}=1,46 \mathrm{~g} / \mathrm{m}^{3}$

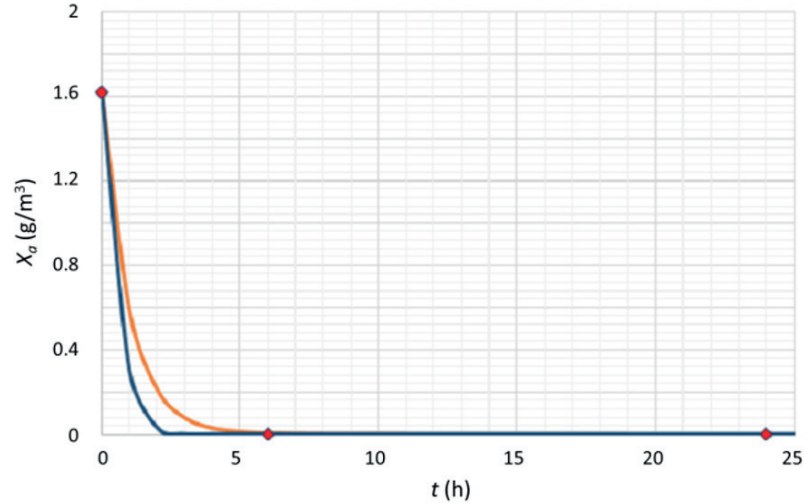

Figure 6. Biomass $X_{a}$ a s a function of time; comparison between model and experimental results for MIT biocide (orange line) and MIT/BIT biocide (blue line); symbols: experimental results (Urška, 2011); $\mathrm{I}^{0}=199 \mathrm{~g} / \mathrm{m}^{3}$ and $\mathrm{X}_{\mathrm{a}}^{0}=1,62 \mathrm{~g} / \mathrm{m}^{3}$ 


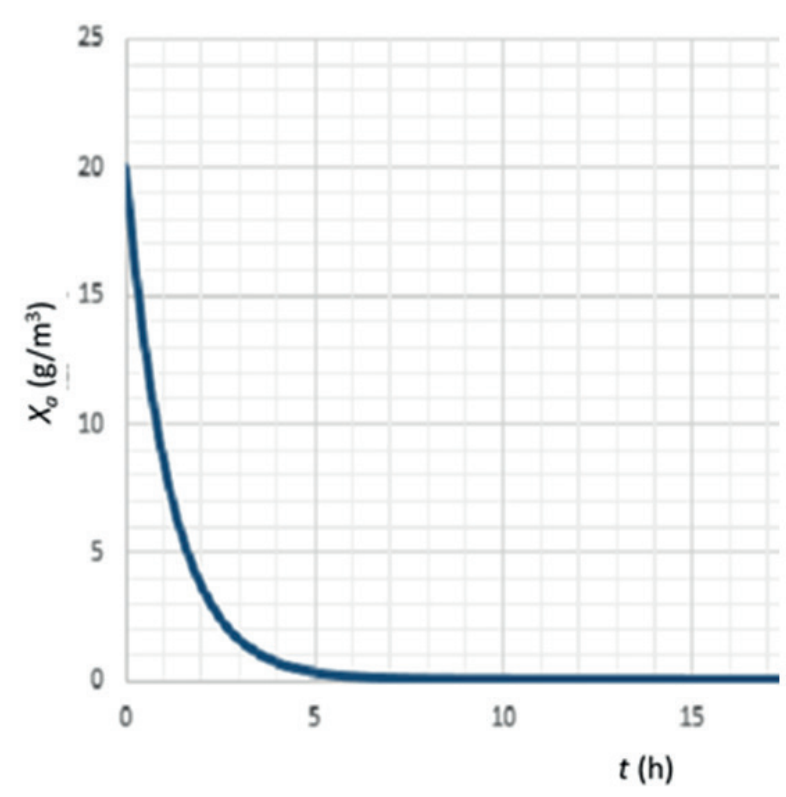

Figure 7. Biomass profile inphase $\mathrm{a}\left(\mathrm{X}_{\mathrm{a}}\right)$ as a function of time; $\mathrm{T}=35^{\circ} \mathrm{C}, \mathrm{I}_{\mathrm{a}}{ }^{\mathrm{a}}=165,9 \mathrm{~g} / \mathrm{m}^{3}$
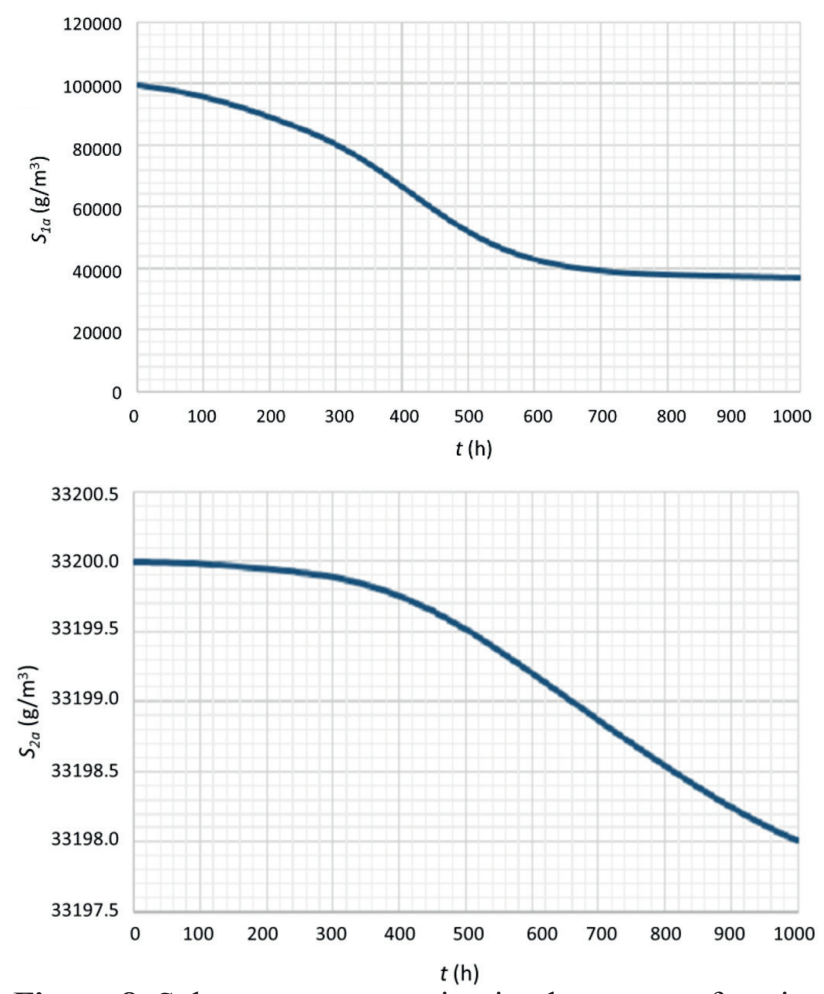

Figure 8. Substrate concentration in phase a as a function of time; $\mathrm{T}=35^{\circ} \mathrm{C}, \mathrm{I}_{\mathrm{a}}^{0}=165,9 \mathrm{~g} / \mathrm{m}^{3}$. a): $\left.\mathrm{S} 1_{\mathrm{a}}, \mathrm{b}\right): \mathrm{S} 2_{\mathrm{a}}$

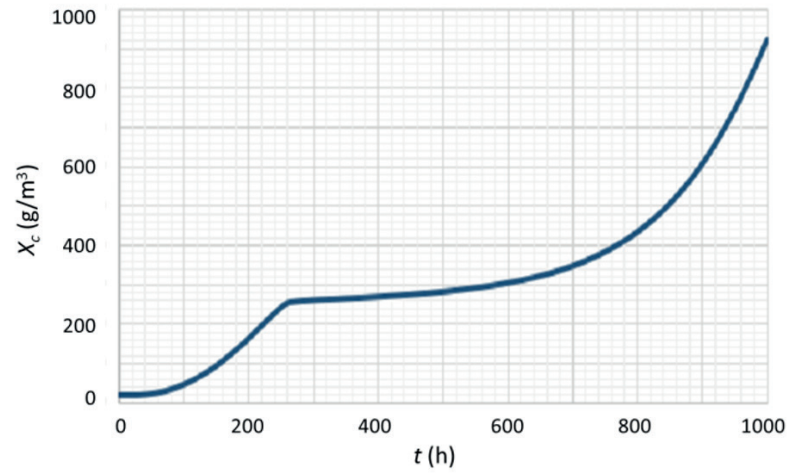

Figure 9. Biomass profile in phase $\mathrm{c}\left(\mathrm{X}_{\mathrm{c}}\right)$ as a function of time; $\mathrm{T}=35^{\circ} \mathrm{C}, \mathrm{I}_{\mathrm{a}}^{0}=165,9 \mathrm{~g} / \mathrm{m}^{3}$
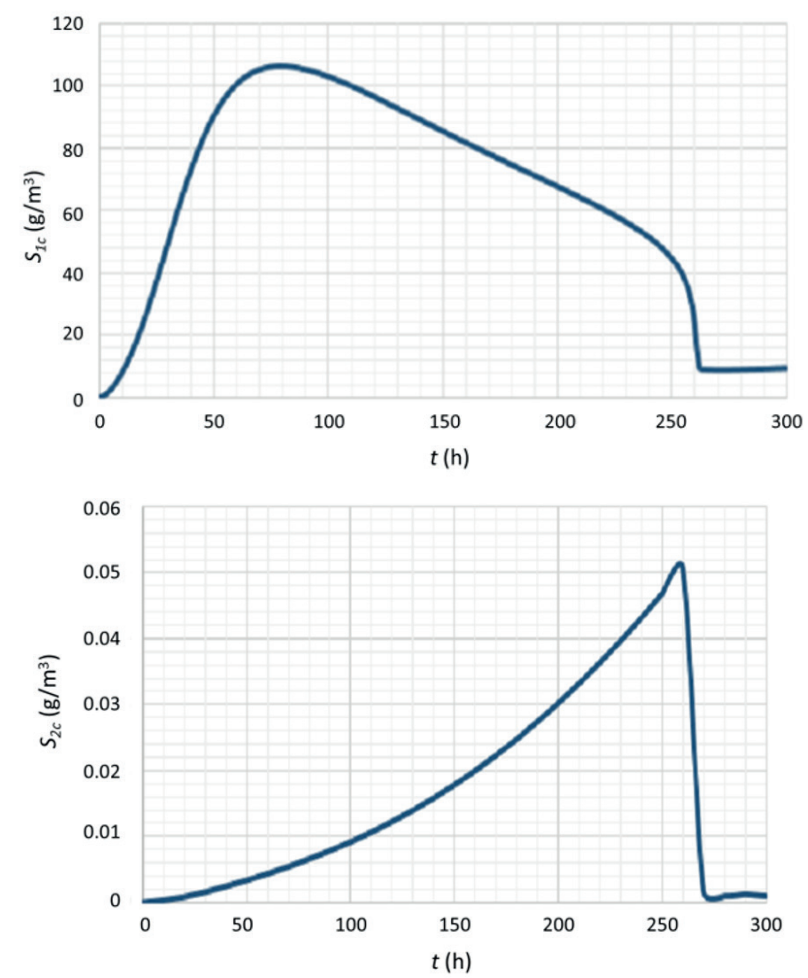

Figure 10. Substrate consumption in phase $\mathrm{c}$ as a function of time; $\mathrm{T}=35^{\circ} \mathrm{C}, \mathrm{I}_{\mathrm{a}}^{0}=165,9 \mathrm{~g} / \mathrm{m}^{3}$. a):S1 $\left.\mathrm{c}, \mathrm{b}\right): \mathrm{S} 2_{\mathrm{c}}$ 

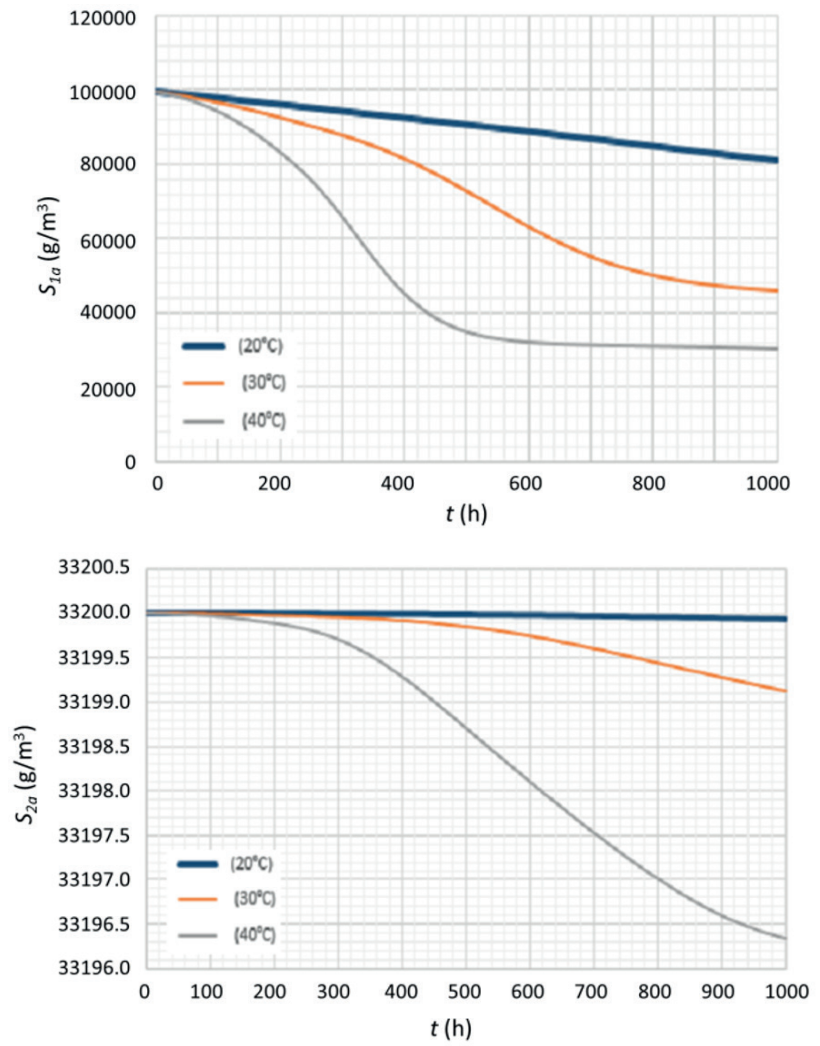

Figure 11. Substrate concentration inphase a as a function of time at the temperatures $\mathrm{T}=20,3040^{\circ} \mathrm{C} ; \mathrm{I}^{0}=165,9 \mathrm{~g} / \mathrm{m}^{3}$. a):S1, b):S2

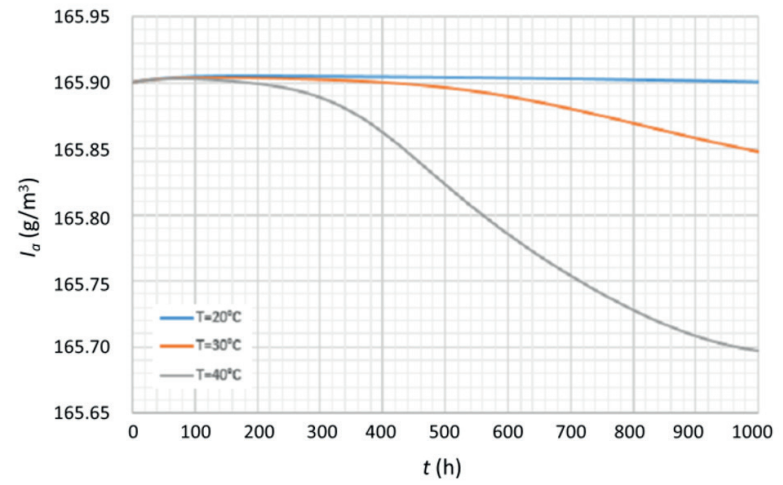

Figure 12. Biocide concentration in phase a as a function of time at the temperatures $\mathrm{T}=20,3040^{\circ} \mathrm{C} ; \mathrm{I}^{0}=165,9 \mathrm{~g} / \mathrm{m}^{3}$.

the growth of biomass.Figure 13a-b shows the substrate concentration $\left(S 1_{c}\right.$ - see Fig.13a; $S 2_{c}$ - see Fig. 13b) in phasec at different temperatures, showing a faster consumption rate at higher temperatures.

A third simulation was intended to determine biomass and substrate profiles with a cyclic sinusoidal temperature profile, with a maximum of $40^{\circ} \mathrm{C}$ and a minimum of
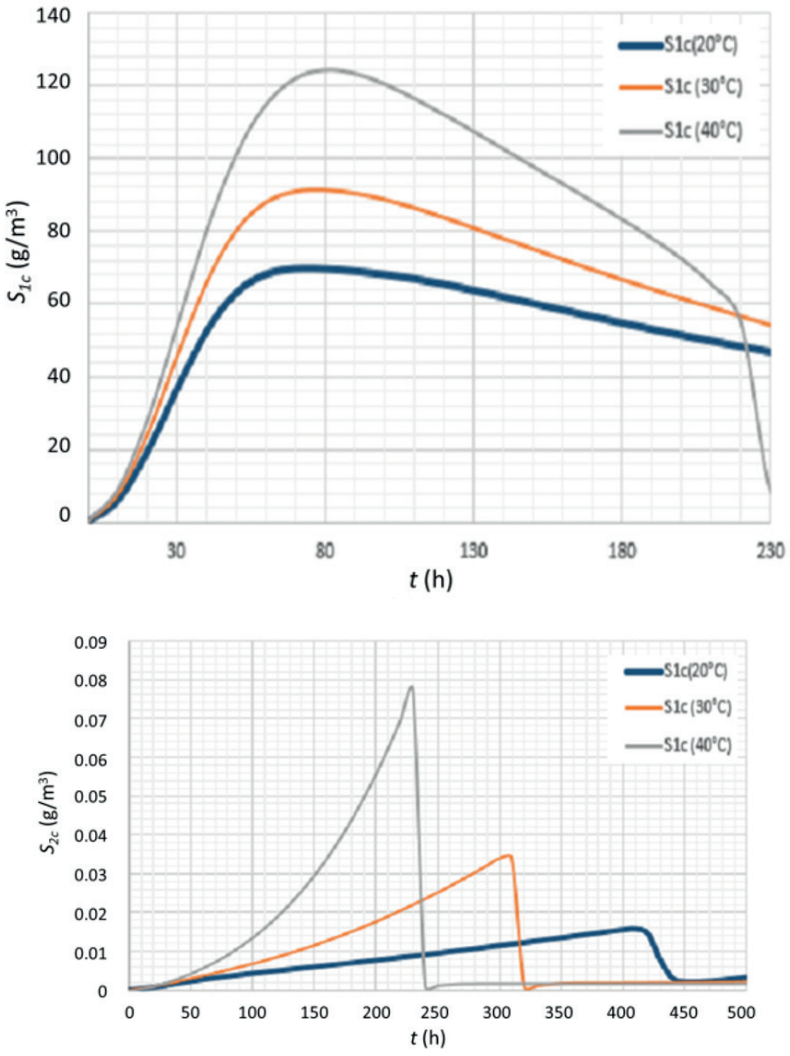

Figure 13a-b. Substrate consumption inphase c as a function of time at the temperatures $\mathrm{T}=20,3040^{\circ} \mathrm{C}$; $\mathrm{I}_{\mathrm{a}}^{0}=165,9 \mathrm{~g} / \mathrm{m}^{3}$. a):S1, b):S2

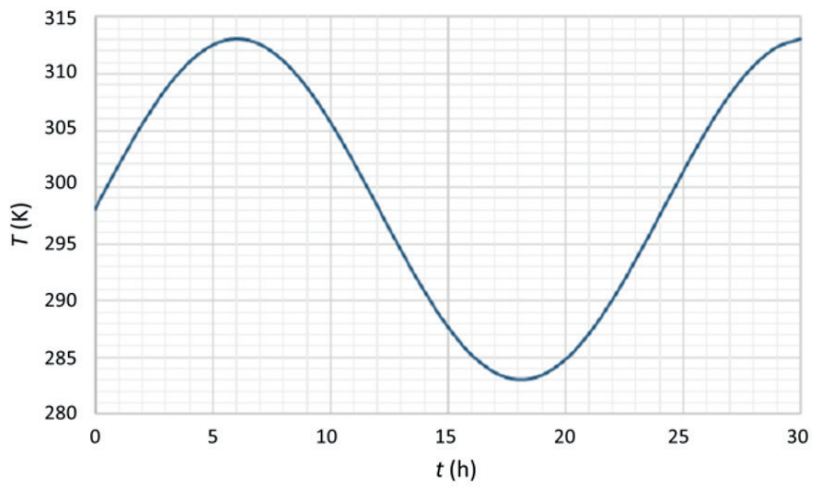

Figure 14. Biomass profile in phase $\mathrm{c}(\mathrm{Xc})$ as a function of time for the sinusoidal temperature profile on Figure 13, $\mathrm{I} 0 \mathrm{a}=165,9 \mathrm{~g} / \mathrm{m} 3$

$10^{\circ} \mathrm{C}$, simulating the exposure of the paint can to night and day temperatures. The most interesting result is that shown in Figure 14, which shows the profile of biomass concentration in phase $c$.

As can be seen, the biomass $X_{c}$ in phase $c$ has a maximum concentration of $1037 \mathrm{~g} / \mathrm{m}^{3}$ (equal to $1.09 \times 10^{9} \mathrm{cfu} / \mathrm{mL}$ ). The upper limit for the concentration ofbacteria is $3.4 \times 10^{10}$ 
$\mathrm{cfu} / \mathrm{mL}$, Therefore, after 1600h (approximately two and a half months), there is a possible critical situation for the system, in which it is likely to have the presence of bacteria in phase $c$ under the lid; however, this maximum bacterial concentration is not achieved with the tested biocide, that appears to be able to provide protection for both the liquid phase and the can. It is to be pointed out also that the considerations are conservative, since in reality the biocide is typically a mixture CMIT/MIT, or MIT/BIT, while the model take into account onlyMIT.

\section{CONCLUSIONS}

In this paper, a model describing the effect of a biocide (MIT) on a water-based paint is presented. The initial biocidal concentration considered in this study is themaximum allowed by the limits of the law, that is, $165.9 \mathrm{~g} / \mathrm{m}^{3}=100 \mathrm{ppm}$. The main result obtained is that the concentration of bacteria in the paint, using a suitable biocide concentration within the limits of the law, decreases with time. This indicates that the chosenbiocideis suitable for the protection of paint for long periods. Moreover, the concentration of bacteria under the cover of the can, in the case of possible evaporation of the product and successive recondensation when subjected to changes in temperatureof the external environment, shows a maximum after about two months anda half. This period is therefore to be considered critical for the possibleformation of bacteria. However, the maximum bacterial concentration achieved at that time in the presence of MIT is always below the allowed limit, so the biocide appears to be able to provide protection for both the liquid phasesaand $c$.

Itis worthnoting that thepresentmodelallowsconsidering the bacterial growth on the coverof the paint can, often underestimated in experimental tests, which focus attention primarily onbacterial behavior only in the bulk of the paint.

Future work will be aimed at verifying the effect of other process parameters, such as initial biocide concentration, and to test the efficacy of different biocides ora mixture of them.

\section{REFERENCES}

AspenTech - Aspen Physical Property, System Physical Property Methods (2011) Version No: V7.3http:// classes.engr.oregonstate.edu/cbee/spring2014/ che432/Aspen $\% 20$ Engineering\%20V7_3/Aspen $\% 20$ Properties/AspenPhysPropMethodsV7_3-Ref.pdf

ASTM Standard test method for resistance of emulsion paints in the container to attack by microorganisms. ASTM International (2012).

Bailey J.E. and D.F. Ollis. Biochemical Engineering Fundamentals. Mc-Graw-Hill (1986).
Bethencourt M, BotanaF.J, Cano M.J, Osuna R.M, Marcos M Degradation mechanism of an acrylic water-based paint applied to steelsProgress in Organic Coatings, 47, 164-168 (2003).

ChemaP., 2015 Information for avoiding of EUH 208 in Paints \& Coatings. www.chemap.cz/wp-content/ uploads/Information_for_avoiding_of_EUH208_in_ Paints.pdf.

ContantS., G.J: Caritá, P.F.M.P.B. Machado, L.M.F. Lona. Evaluation of the effect of dry-film biocides on paint film preservation using neural networksBraz. J. Chem. Eng.,27,643-651 (2010).

Del Amo, B., Romagnoli, R., Deyá, C., and González, J. A. High performance water-based paints with non-toxic anticorrosive pigments. Progress in Organic Coatings, 45, 389-397 (2002).

Goossens, E. L. J., van der Zanden, A. J. J., Wijen, H. L. M., and van der Spoel, W. H. The measurement of the diffusion coefficient of water in paints and polymers from their swelling by using an interferometric technique. Progress in Organic Coatings, 48, 112-117 (2003).

KarsaD.R., D. Ashworth. Industrial biocides selection and application, R. S. C.Cambridge CB4 OWF, UK, 2002.

Kasperczyk D., G. Bartelmus, A. Gąszczak.Clean processes - Biodegradation kinetics andmathematical modelling of microbial removal of vinylacetate from dilute gaseous waste streamsChemEng Trans., 11:665670 (2007).

Kham A.A.H., S.M. Karuppayil SM. Fungal pollution of indoor environments and its management. Saudi J. Biol. Sci.19, 405-426 (2012).

Kompala D.S.. Bioprocess Engineering: Fundamentals and Applications. CRC Press(2013).

La Rosa F.R., E.C. Giese, R.F.H. Dekker, J. S. Pelayo, A. M. Barbosa. Microbiological contamination of water-basd paints from an industry in the state of Paraná, Brazil. Ciências Exatas Ciências Exatas e Tecnológicase da Terra, Londrina. 29, 85-92 (2008).

Obidi O.F., O.O. Aboaba, M.S. Makanjuola, S.C. Nwachukwu. Microbial evaluation and deterioration of paints and paint-products. $J$ Environ Biol., 30, 835-840 (2009).

Olufemi, O.L., M.O. Kolawole, A.S. Joshua. Isolation and Characterization of Fungi Associated with in-Can Degradation of Paint $J$ Environ. Earth Sci., 3, 142-145 (2013).

Piemonte V., Capocelli M., Tortora F., Prisciandaro M. Criteria for evaluating the microbiological contamination of acrylic paints, Chemical Engineering Transactions (2016) 49: 7-12. 
Pöllmann P. and M. Löbbecke. Gas Separation \& Purification, 10,177-180 (1996).

Ravikumar, H.R., Shwetha S. Rao S.S., C.S.B KarigarC.S.B. Biodegradation of Paints: a Current StatusIndian J. Sci. Tech., 5, 1977-1087 (2012).

Renon H. and J.M. Prausnitz. Local composition in thermodynamic excessfunctions for liquid mixtures. AICHE Journal,14, 135-144 (1968).

Toscano G., L. Cavalca; M. Letizia Colarieti; R. Scelza; R. Scotti; M. Rao; V. Andreoni; S. Ciccazzo; G. Greco Aerobic biodegradation of propylene glycol by soil bacteria.Biodegradation 24, 603-613 (2013).
Ulbrich M., Kalendová A. Properties of organic coatings with nonisometric ferrite particles Physics Procedia 44, $247-255$ (2013).

UngerA., A. Schniewind, W. Unger. Conservation of Wood Artifacts: A Handbook. Springer Science \& Business Media (2013).

UrškaT.. Isolation of microorganisms from water-based paint manufacturing plant and analysis of efficiency of biocides. Graduation thesis. Department of Food Science and Technology, University of Ljubljana (2001).

Villadsen J., J. Nielsen, G. Lidén. Bioreaction Engineering Principles. Springer (2011). 